\title{
ÉPOCAS DE COLHEITA E QUALIDADE FISIOLÓGICA DAS SEMENTES DE ARROZ IRRIGADO CULTIVAR BRS 7 TAIM, EM RORAIMA ${ }^{1}$
}

\author{
OSCAR JOSÉ SMIDERLE², PAULO ROBERTO VALLE DA SILVA PEREIRA ${ }^{3}$
}

\begin{abstract}
RESUMO - A época de colheita é um dos fatores mais importantes que influenciam as características da semente de arroz, seja para semeadura ou para consumo. Com o objetivo de determinar a época adequada de colheita do arroz (Oryza sativa L.) irrigado BRS 7 TAIM, sementes dessa cultivar foram colhidas aos 15, 22, 29, 36, 43 e 50 dias após o florescimento (DAF) e avaliadas quanto à umidade, produtividade, peso seco de 100 sementes, rendimento de grãos inteiros, viabilidade e armazenabilidade. As colheitas realizadas aos 15 e 22 DAF revelaram-se impróprias, obtendose valores inferiores em todas variáveis estudadas, além de alta umidade inicial das sementes. As sementes colhidas aos 29 DAF tiveram alta qualidade, porém, a produtividade foi inferior à dos períodos subseqüentes; as provenientes da colheita aos 50 DAF exibiram bom desempenho, exceto no rendimento de grãos inteiros. A melhor época de colheita para a cultivar Taim ocorre entre 38 e 42 DAF, quando as sementes apresentam índices superiores de produtividade, peso seco, rendimento de grãos inteiros, qualidade fisiológica e armazenabilidade.
\end{abstract}

Termos para indexação: Oryza sativa, qualidade fisiológica, umidade, Roraima.

\section{HARVESTING TIME AND PHYSIOLOGIC QUALITY OF CULTIVAR BRS 7 TAIM THE IRRIGATED RICE SEEDS IN RORAIMA}

\begin{abstract}
Harvesting time is one of most important factors which influence rice seed characteristics for the purpose of planting or milling. With the objective to determine the proper period of harvesting of irrigated rice (Oryza sativa L.) the seeds of BRS 7 TAIM cultivar were harvested at at 15, 22, 29, 36, 43 and 50 days after flowering, dryed, processed for cleaning purpose and evaluated in relation to moisture, productivity, dry weight of 100 seeds, undamaged rice yield, viability and storability. Seeds harvested at 15 and 22 days after flowering showed low performance exhibiting deficiency in all variables studied, besides high initial humidity. Seeds harvested at 29 days showed hight quality, but yield was lower than those of later periods. Those obtained from harvest at 50 days showed good performance, with exception for undamaged rice yield. The best harvesting period considering TAIM cultivar is between 38 an 42 days after flowering, when seeds present high rates of quality, yield, dry weight, undamaged rice yield, physiological quality and storability.
\end{abstract}

Index terms: Oryza sativa, physiological quality, moisture, Roraima.

${ }^{1}$ Submetido em 08/02/2007. Aceito para publicação em 25/10/2007.

${ }^{2}$ Pesquisador DSc. Embrapa Roraima. CP 133 CEP 69301-970. Boa Vista RR. e-mail: ojsmider@cpafrr.embrapa.br
${ }^{3}$ Pesquisador Dr. Embrapa Trigo. Passo Fundo, RS. e-mail: prvsp@cnpt.embrapa.br 


\section{INTRODUÇÃO}

A qualidade física e fisiológica da semente de arroz depende da cultivar, estádio de maturação, conteúdo de umidade e danos mecânicos (impactos, abrasões e tensões) que podem ocorrer durante a colheita, secagem, beneficiamento e mesmo no armazenamento.

A maioria das cultivares apresentam redução no rendimento de grãos inteiros após atingirem determinado grau de maturação. Grãos muito secos ficam sujeitos a rachaduras no campo, que favorecem sua quebra nas operações de colheita e posterior beneficiamento. Altas percentagens de grãos quebrados diminuem sensivelmente o tipo e o valor comercial de um lote de arroz (Faroni et al., 1987).

Colher na época certa é de fundamental importância para se obter um produto de melhor qualidade e com maior rendimento. As sementes de arroz atingem o ponto de maturação adequado quando dois terços das sementes da panícula estão maduras. A colheita antecipada, com umidade elevada, aumenta a proporção de grãos malformados e gessados. $\mathrm{O}$ arroz colhido tardiamente, com umidade muito baixa, afeta a produtividade pela degrana natural, ocorrendo o trincamento dos grãos e a redução do rendimento de grãos inteiros no beneficiamento.

Arroz trincado é também mais susceptível à infestação por insetos. O trincamento também tem a desvantagem de poder reduzir a viabilidade ou o valor de plantio do arroz para semente. Trincas que ocorrem através de toda a secção do grão diminuem o vigor da plântula pela redução da disponibilidade de endosperma, e, conseqüentemente, de nutrientes durante a fase de germinação e emergência (Steffe et al., 1980).

Colheita precoce resulta em decréscimo na produção pelo desenvolvimento incompleto das sementes, que se apresentam, com alto conteúdo de umidade, freqüentemente gessadas. Um excessivo número de sementes imaturas também é produzido quando do cultivo de variedades de maturação desuniforme. Grãos gessados, além de conferirem má aparência ao produto acabado, são mais fracos e quebram-se nas operações de beneficiamento (Morse et al., 1967, Juliano, 1980, Luh e Mickus 1991; Webb, 1980). Grãos completamente gessados são, normalmente, imaturos, colhidos precocemente e, conseqüentemente, mais frágeis (Castro et al., 1999) podendo variar em função da cultivar, ambiente e processos de pós-colheita (Juliano e Duff, 1991). Ojayi e Clark (1997) afirmam que a magnitude do dano causado, durante o processamento, depende das propriedades físicas e mecânicas dos grãos.
O estádio de maturação também influencia a viabilidade e o vigor dos sementes de arroz para fins de semeadura. O ponto de completa maturação da semente é geralmente considerado como aquele em que ela atinge o máximo peso seco durante a fase de desenvolvimento e maturação no campo (Rajanna e Andrews 1970, Gonçalo e Maciel, 1975). Em São Paulo, Lago et al. (1991) verificaram que o melhor intervalo de colheita da cultivar IAC 4440 (arroz irrigado) é o de 36 a 43 DAF. Sementes colhidas antes da completa maturação são mais leves, mal formadas e menos vigorosas, com reflexos negativos no armazenamento e após o plantio no campo.

A dormência em sementes de arroz, principalmente quando recém-colhidas, pode apresentar obstáculos à sua análise, comercialização e plantio imediato. A intensidade e persistência dessa dormência varia grandemente com a cultivar. Variações semelhantes entre cultivares de arroz foram constatadas por Lago et al. (1977) e Tella et al. (1977). Vieira (1975) verificou que a dormência das sementes da cultivar Nato foi muito intensa até 35 dias após a antese, com germinação de apenas $10 \%$.

Embora o período de dormência das sementes de arroz varie entre cultivares, podendo persistir de 90 a 120 dias (Franco et al. 1997), as condições de armazenamento principalmente com a elevação da temperatura, segundo Bewley e Bleck (1994), podem reduzir esse período, proporcionando aumentos significativos na germinação das sementes.

A preservação da qualidade fisiológica das sementes mantidas em armazém convencional é um dos desafios enfrentados pela tecnologia de sementes. No armazenamento a longevidade das sementes está sujeita à ação de fatores externos que afetam a qualidade.

Em face da escassez de informações de caráter regional sobre a influência da colheita e do armazenamento na qualidade de sementes de arroz irrigado, e à medida que se dá maior ênfase à qualidade de sementes tanto para consumo como plantio, com a presente pesquisa objetivouse, determinara a época mais adequada de colheita visando produtividade, qualidade fisiológica de sementes, rendimento de engenho e armazenabilidade de sementes de arroz cv. BRS 7 Taim, produzidas em Boa Vista/ RR.

\section{MATERIAL E MÉTODOS}

$\mathrm{O}$ experimento foi instalado em área irrigada por inundação, em solo classificado como GLEISSOLO HÁPLICO Tb Distrófico, localizada na Fazenda Santa 
Cecília, município do Cantá, Estado de Roraima. A cultivar de arroz (Oryza sativa L.) estudada foi a 'BRS 7 TAIM'. Cada parcela experimental constou de quatro linhas de seis metros de comprimento, espaçadas $0,30 \mathrm{~m}$ entre si, e nas colheitas foram aproveitadas apenas as duas linhas centrais.

As propriedades químicas do solo do experimento foram as seguintes: $\mathrm{P}$ (Mehlich-1) traços; MO 20,6 $\mathrm{g} \mathrm{dm}^{-3} ; \mathrm{pH}$ (água) 5,2; K 48,64 mg dm${ }^{-3}$; Ca 0,67 $\mathrm{cmol}_{\mathrm{c}} \mathrm{dm}^{-3} ; \mathrm{Mg} \mathrm{0,33}$ $\mathrm{cmol}_{\mathrm{c}} \mathrm{dm}^{-3}$. No plantio nas parcelas experimentais, foram aplicados $100 \mathrm{~kg} \mathrm{ha}^{-1} \mathrm{de}_{2} \mathrm{P}_{5}$ e $80 \mathrm{~kg} \mathrm{ha}^{-1} \mathrm{de}_{2} \mathrm{O}$ nas formas de superfosfato simples e de cloreto de potássio, respectivamente. A adubação nitrogenada, na forma de sulfato de amônio, foi parcelada, sendo aplicados $60 \mathrm{~kg} \mathrm{ha}^{-1}$ de $\mathrm{N}$ no perfilhamento e $60 \mathrm{~kg} \mathrm{ha}^{-1}$ na diferenciação do primórdio floral (15 e 45 dias após a emergência, respectivamente). As práticas culturais utilizadas, para a implantação e condução dos experimentos, foram efetuadas de acordo com as recomendações técnicas para a cultura do arroz irrigado em Roraima.

Por ocasião do cacheamento, o campo foi vistoriado diariamente para a determinação da data do florescimento, ou seja, do estádio de antese quando havia aproximadamente $50 \%$ das espiguetas abertas, considerado como o início do período de desenvolvimento e maturação dos grãos (Stansel, 1975).

As colheitas foram iniciadas quinze dias após o florescimento, quando pelo menos um grão da panícula do colmo principal apresentava maturidade $\mathrm{R}_{7}$ (Counce et al., 2000) e, então, a intervalos de sete dias, até o total de 50 dias, passando pelos estádios $\mathrm{R}_{8}$ e $\mathrm{R}_{9}$ descritos por Counce et al. (2000) e validados para cultivares brasileiras de arroz irrigado por Freitas et al. (2006). As panículas foram colhidas manualmente no campo. A trilha foi realizada em trilhadeira estacionária e, em seguida, as sementes foram embaladas em sacos de plástico para minimizar perdas de umidade e levadas ao laboratório. As sementes obtidas foram imediatamente avaliadas quanto ao grau de umidade. Deteminou-se ainda o grau de umidade (base úmida), para cada colheita, utilizandose duas amostras de 100 sementes cada, que foram mantidas em estufa a $105^{\circ} \mathrm{C}$ por 24 horas (Brasil, 1992).

Logo após as colheitas, as sementes foram secas a $40^{\circ} \mathrm{C}$, por 48 a 72 horas, até atingirem umidade em torno de $13 \%$, e então colocadas em condições ambientes de armazém por três dias para a uniformização da umidade no interior dos grãos, quando então foram feitas novas avaliações de conteúdo de umidade das sementes para verificar os valores obtidos para o armazenamento. Os valores de umidade das sementes estavam em torno de $11 \%$. O rendimento de grãos inteiros foi ajustado para $13 \%$ de umidade e transformado em $\mathrm{kg} \mathrm{ha}^{-1}$. Avaliou-se também a qualidade fisiológica das sementes pelo teste de germinação e primeira contagem de germinação (vigor) bem como o rendimento de grãos inteiros. O teste de germinação foi realizado com quatro amostras de 100 sementes cada, que foram colocadas em substrato papel de germinação, formando rolos, mantidas em germinador a temperatura constante de $25^{\circ} \mathrm{C}$. A primeira contagem foi realizada aos cinco dias e a última aos quatorze dias após a semeadura (Brasil, 1992).

O rendimento de grãos inteiros, após beneficiamento para consumo, foi avaliado com duas amostras de $100 \mathrm{~g}$ por repetição, em engenho de prova, marca "SUZUKI" (Dorfman e Rosa, 1980, Infeld e Silveira Júnior, 1984; Lago et al., 1991) logo após a uniformização da umidade. Depois disto, as sementes remanescentes foram mantidas em condições comuns de armazém na Embrapa Roraima, em recipientes de papel, e novos testes de germinação e rendimento de engenho foram realizados aos 6 e 12 meses, a fim de se determinar a qualidade fisiológica das sementes e o rendimento de grãos inteiros.

O delineamento experimental utilizado foi o inteiramente aleatorizado, composto de seis tratamentos (colheita aos 15; 22; 29; 36; 44 e 50 DAF), três períodos de avaliação (zero; seis e doze meses) e quatro repetições. Para comparação dos resultados, foram realizadas análises de variância, fazendo transformação dos valores expressos em percentagem para arco seno $\sqrt{\mathbf{x}+1 / 2}$. Para as variáveis que apresentaram efeito significativo pelo teste $\mathrm{F}$, realizaram-se análises de regressão. Para as análises estatísticas utilizou-se o programa SAS (2003).

\section{RESULTADOS E DISCUSSÃO}

Os resultados obtidos nas determinações de grau de umidade, peso seco de 100 grãos, produtividade e grãos inteiros de arroz estão representados nas Figuras 1, 2 e 3.

Foi observado pelos resultados obtidos para a determinação do conteúdo de umidade dos grãos, nas seis colheitas realizadas, diferenças significativas apresentando redução constante ao longo do período seguindo a equação de regressão linear $y=35,295-0,3059 x$ e $R^{2}$ de 0,9527 (Figura 1).

Para o peso seco de 100 grãos obteve-se valor máximo de 2,483g de 39 a 41 DAF, próximo da quinta colheita (Figura 2). Rajanna e Andrews (1970), estudando a maturação de sementes de arroz da cultivar Bluebonnet-50, constataram que o máximo peso seco foi atingido em período antecipado, ou seja, dos 25 a 30 dias após a antese. Esse ponto em que o 


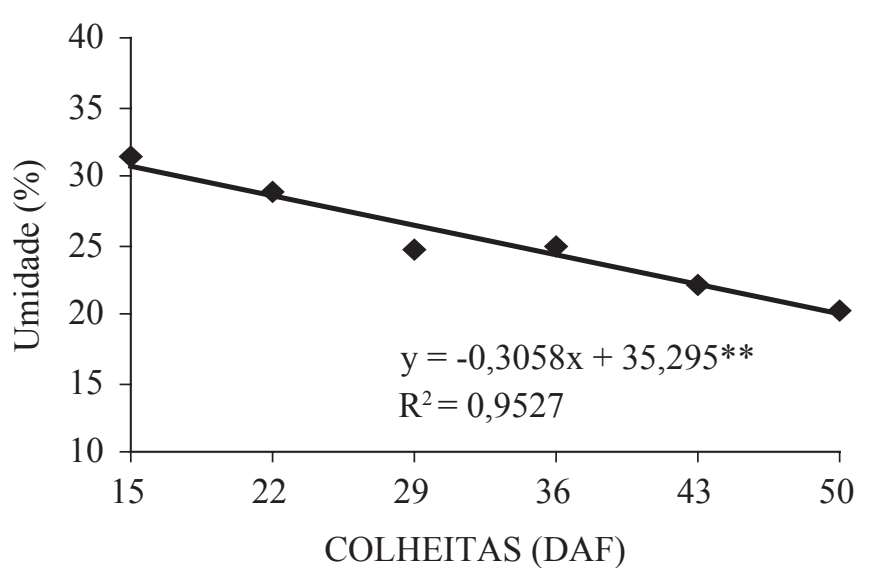

FIGURA 1. Valores médios do grau de umidade (\%) das sementes de arroz, cv. BRS 7 Taim, colhidas em diferentes épocas em Boa Vista - RR.

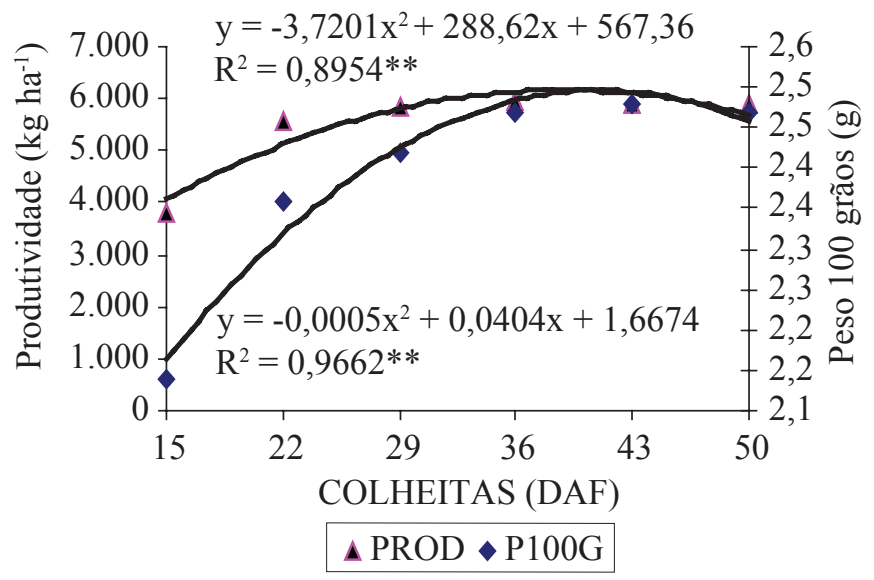

FIGURA 2. Valores médios de produtividade de grãos (PROD, kg ha-1) e peso de 100 grãos (P100G, g) de arroz, cv. BRS 7 Taim, colhidos em diferentes épocas em Boa Vista - RR.

mais alto valor de peso seco é obtido, coincide, normalmente com o ponto de máxima qualidade fisiológica de sementes (Carvalho e Nakagawa, 2000).

A produtividade de grãos aumentou acentuadamente com o desenvolvimento e maturação dos grãos nas seis colheitas (Figura 2). A produtividade máxima foi obtida aos $39 \operatorname{DAF}\left(6.165 \mathrm{~kg} \mathrm{ha}^{-1}\right)$, com teor de água relativamente alto, próximo de $24 \%$ (Figura 1). A produtividade tendeu a reduzir até a última colheita realizada aos 50 DAF $\left(5.871 \mathrm{~kg} \mathrm{ha}^{-1}\right)$. Essa produtividade foi obtida quando o material apresentava umidade adequada para a colheita $(20,33 \%)$, porém com

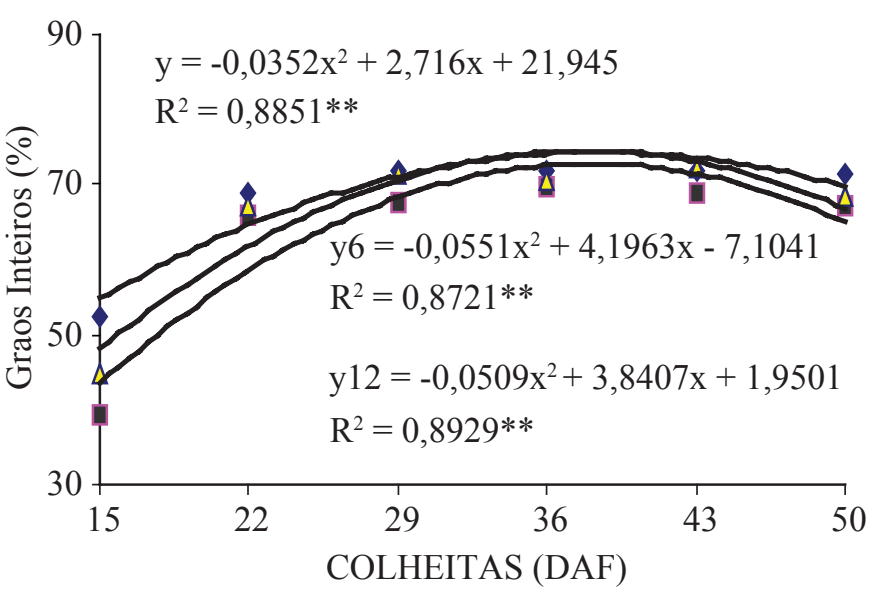

FIGURA 3. Valores médios de grãos inteiros (\%) de arroz, cv. BRS 7, Taim colhidos em seis épocas e armazenados por 0,6 e 12 meses em Boa Vista, RR.

tendência de redução no rendimento de grãos inteiros (Figura 3). Steffe et al (1980) relataram que as variedades de arroz testadas na Califórnia alcançam o rendimento máximo de grãos inteiros com conteúdo de água um pouco mais alto do que aquele em que ocorre o máximo de produtividade, como foi constatado com a cultivar "BRS 7 Taim" (Figuras 1 e 3).

$\mathrm{O}$ rendimento de grãos inteiros apresentou tendência polinomial, crescente dos 15 aos 38 DAF; a partir dai, permaneceu estável até 42 DAF (Figura 3). Os menores valores foram observados entre 15 e 22 DAF, o que pode ser atribuído à imaturidade, formação incompleta e gessamento das sementes (Lago et al., 1991; Castro et al., 1999). O aumento de grãos quebrados, ocorrido dos 43 aos $50 \mathrm{DAF}$, foi causado possivelmente, pelo tempo excessivo que as sementes permaneceram no campo após a maturação completa. Podendo ainda ser atribuído a cultivar de arroz e processos de pós-colheita (Juliano e Duff, 1991).

Infeld e Silveira Júnior (1984) determinaram os pontos de colheita para quatro cultivares de arroz na região de Pelotas, RS, verificando para a cultivar Lebonnet rendimento máximo de grãos inteiros $(64,9 \%)$ aos 34 DAF, com teor de água de $18,5 \%$. O rendimento máximo para a cultivar Bluebelle ocorreu aos 38 dias, com teor de água de 19,5\%. Estes períodos são próximos dos obtidos para a cv. Taim. No entanto, esta cultivar apresentou maior percentual de grãos inteiros, variação que pode ser atribuída a característica própria da cultivar (Juliano e Duff, 1991).

É importante observar que retardar a colheita de arroz com o objetivo de colher material mais seco, o que exige 
menos gasto com mão-de-obra e energia para secagem do arroz, pode ser anti-econômico quando as perdas decorrentes pela quebra de grãos e desvalorização do lote sobressaem aos ganhos oriundos do menor custo de secagem. Chuvas na colheita e outros fatores adversos durante o armazenamento das sementes, dependendo das propriedades das sementes podem resultar em maior ou menor danos (Ojayi e Clark, 1997).

Verificando ainda o comportamento no rendimento de grãos inteiros nas avaliações realizadas ao longo do armazenamento (6 e 12 meses, Figura 3), define-se a faixa de 34 a 42 DAF como a de maior rendimento, semelhante ao verificado imediatamente após a colheita, sendo apresentadas tendências de percentuais semelhantes, com reduzida perda no período avaliado. Estes resultados obtidos durante o armazenamento indicam que o processo de secagem realizado não interferiu na qualidade física das sementes (Faroni et al., 1987). A utilização de temperaturas de secagem elevadas poderiam ter ocasionado perdas. Nas três avaliações houve uma tendência de aumento do rendimento de 15 para 22 DAF, e deste para 29 DAF onde praticamente estabiliza até a quinta colheita, tendendo a reduzir a partir dai até a colheita realizada aos 50 DAF (Figura 3).

Nas Figuras 4 e 5 verifica-se o comportamento polinomial dos valores médios percentuais de germinação e vigor das sementes de arroz BRS 7 Taim durante 12 meses de armazenamento em condição ambiente de laboratório. Imediatamente após a colheita (zero mês), as percentagens de germinação foram semelhantes em todas as épocas avaliadas, com destaque para o período de 29 a 43 DAF $\left(y=83,067+0,7424 x-0,0095 x^{2} ; R^{2}=0,8115\right.$, Figura 4). O vigor das sementes foi crescente até 38 DAF (81\%), tendo posteriormente decréscimo aos 50 DAF (Figura 5). Gonçalo e Maciel (1975), estudando a maturação de sementes arroz 'EEA-404', em Pelotas (RS), verificaram, aos 22 dias após a antese, valores de vigor próximos de $90 \%$, porém pontos máximos simultâneos para germinação, vigor e peso seco foram obtidos aos 36 dias.

As sementes colhidas aos 15 DAF e nos períodos subseqüentes, apresentaram excelente armazenabilidade, com germinação entre 90 e 96\% mesmo após 12 meses de armazenamento (Figura 4). Verificou-se, aos 12 meses após a colheita, tendência de perda de qualidade maior para as sementes colhidas a partir de 43 DAF. Nas sementes de arroz BRS 7 Taim, tanto na colheita quanto no armazenamento verificou-se baixos percentuais de sementes dormentes nos testes de germinação. Nesse aspecto, possivelmente a secagem realizada nas sementes logo após a colheita pode ter

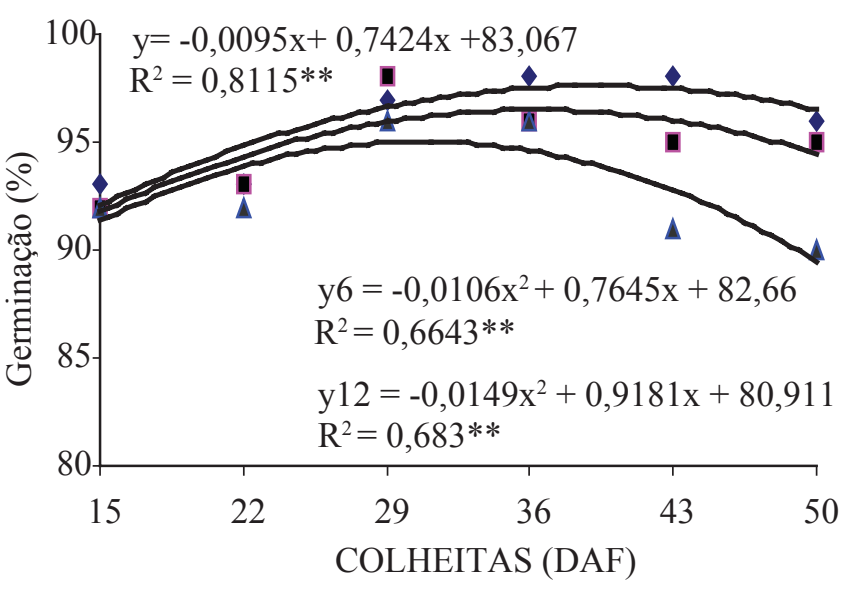

FIGURA 4. Valores médios de germinação (\%) de sementes de arroz, cv. BRS 7 Taim, colhidas em seis épocas e armazenadas por 0,6 e 12 meses em Boa Vista, RR.

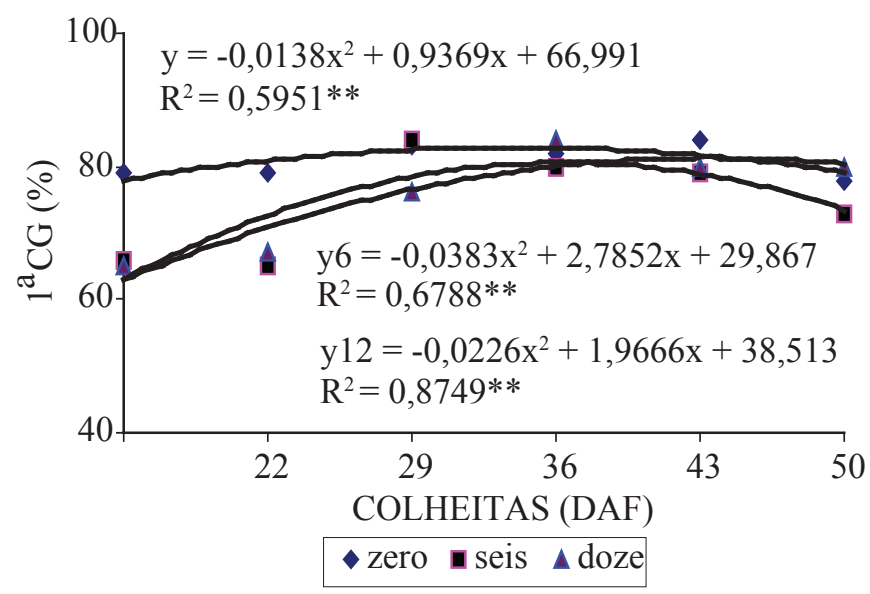

FIGURA 5. Valores médios de vigor ( $\left(1^{\text {a }} \mathrm{CG}, \%\right)$ de sementes de arroz, cv. BRS 7 Taim, colhidas em seis épocas e armazenadas por 0,6 e 12 meses em Boa Vista, RR

contribuído (Bewley e Black, 1994) ou ser uma característica não manifestada pela cultivar em estudo ou mesmo uma resposta às condições de cultivo e/ou ainda armazenamento.

Aindaquecomboaviabilidadenoiníciodoarmazenamento, as sementes das duas primeiras colheitas apresentaram menor armazenabilidade quando comparadas às demais, sendo mais frágeis (Castro et al., 1999), destacadamente no vigor para aquelas sementes colhidas aos 15 dias, cujo vigor foi inferior a 70\% (Figura 5). No entanto, a germinação foi semelhante a 
das colhidas aos 43 e 50 DAF e estas apresentaram menores valores de germinação no armazenamento (Figura 4).

As sementes colhidas aos 29 DAF tiveram alta qualidade fisiológica, porém apresentando produtividade de grãos (Figura 2) inferior à dos períodos imediatamente subseqüentes (36 e 43 DAF). Sementes provenientes da colheita realizada aos 50 DAF tiveram bom desempenho, porém, com tendência de decréscimo na qualidade fisiológica. Já o rendimento de grãos inteiros teve decréscimo mais acentuado, sendo comparativamente mais prejudicado.

O comportamento insatisfatório dessas sementes, ainda imaturas e mal formadas, com maior fragilidade (Castro et al., 1999) durante o armazenamento, revela que a germinação não pode ser considerada separadamente como índice de qualidade de sementes durante a maturação, pois os altos valores de viabilidade inicial não foram substanciados por outros fatores de qualidade. Ao contrário, elas mostraram deficiências não só quanto à armazenabilidade mas também com relação ao peso seco e rendimento de grãos inteiros (Figuras 2 e 3 ).

\section{CONCLUSÕES}

Colheitas realizadas aos 15 e 22 DAF são impróprias, reduzindo a qualidade fisiológica das sementes e o rendimento;

A época mais adequada para a colheita de sementes da cultivar Taim ocorre entre $38 \mathrm{e} 42 \mathrm{DAF}$, quando as sementes apresentam índices superiores de qualidade fisiológica, peso seco, rendimento de grãos inteiros, produtividade e armazenabilidade.

\section{REFERÊNCIAS}

BEWLEY, J.D.; BLACK, M. Seeds: physiology of development and fermination. 2.ed. New York: Plenum Press. 1994. 445p.

BRASIL. Ministério da Agricultura e da Reforma Agrária. Regras para análise de sementes. Brasília: SNDA/DNDV/ CLAV, 1992. 365p.

CARVALHO, N.M. de; NAKAGAWA, J. Sementes: ciência, tecnologia e produção. 4.ed. Jaboticabal: FUNEP, 2000. $588 \mathrm{p}$.

CASTRO, E. da M. de: VIEIRA, N.R. de A.; RABELO, R.R.; SILVA, S.A. da. Qualidade de grãos em arroz. Santo Antônio de Goiás: Embrapa Arroz e Feijão, 1999. 30p. (Embrapa Arroz e Feijão. Circular Técnica, 34).

COUNCE, P.A.; KEISLING, T.C.; MITCHELL, A.J. A uniform, objective, and adaptative system for expressing rice development. Crop Science, Madison, v.40, p. 436-443. 2000.
DORFMAN, E.; ROSA, J.L.V. Ponto de colheita e temperatura de secagem na qualidade do arroz. Lavoura Arrozeira, Porto Alegre. v.33, n.318, p.69-74. 1980.

FARONI, L.R.D.; HARA, T.; DALPASQUALE, V.A.; CONDÉ, A.R. Determinação do rendimento do arroz (cultivar IR 841) após secagem às temperaturas de 50,60 e $70^{\circ} \mathrm{C}$, para períodos de repouso de 30, 60, 120 e 180 minutos. Revista Brasileira de Armazenamento, Viçosa, v. 11/12, n. 1/2, p. 26-31, 1986/1987.

FRANCO, D.F.; PETRINI, J.A.; RODO, A.; OLIVEIRA, A.; TAVARES, W.R.F. Métodos para superar a dormência em sementes de arroz (Oryza sativa L.). Informativo ABRATES, Curitiba, v.7, n.1/2, p.118. 1997.

FREITAS, T.F.S., SILVA, P.R.F., STRIEER, M.L. SILVA, A.A. Validação de escala de desenvolvimento para cultivares brasileiras de arroz irrigado. Ciência Rural, Santa Maria, v.36 n.2, p. 404-410, mar-abr, 2006.

GONÇALO, J.F.P.; MACIEL, V.S. Maturação fisiológica de sementes de arroz (Oryza sativa L.). Semente, Brasília, v.1, n.1, p.21- 25. 1975.

INFELD, J.A.; SILVEIRA JR., P.S. Época de colheita e rendimento de engenho de quatro cultivares de arroz irrigado. Pesquisa Agropecuária Brasileira, Brasília, v.19, n.5, p.599-604. 1984.

JULIANO, B.O. Properties of the rice caryopsis. In: LUH, B.S. (ed.) Rice: production and utilization. Westport: Connecticut AVI Publishing, 1980. p.403- 438.

JULIANO, B. O.; DUFF, B. Rice grain quality as an emerging priorityinnationalricebreedingprograms. In:INTERNATIONAL RICE RESEARCH INSTITUTE. Rice grain marketing and quality issues. Manila: IRRI, 1991. p. 55-64

LAGO, A.A.; FURLANI, P.R.; AZZINI, L.E. Efeito da temperatura de $50^{\circ} \mathrm{C}$ na quebra da dormência de sementes de arroz. Bragantia, Campinas, v.36, p.XI-XIII. 1977.

LAGO, A.A.; VILLELA, O.V.; MAEDA, J.A.; RAZERA, L.F.; TISSELLI FILHO, O.; MARCHI, L.O.S. Época de colheita e qualidade das sementes da cultivar de arroz irrigado 'IAC-4440'. Pesquisa Agropecuária Brasileira, Brasília, v.26, n.2, p.263-268. 1991.

LUH, B.S.; MICKUS, R.R. Parboiled rice. In: LUH, B.S. (ed.) Rice. Volume II: Utilization, Van Nostrand Reinhold, New York (1991), pp.51-88.

MORSE, M.D.; LINDT, J.H.; OELKE, E.A.; BRANDON, M.D.; CURLEY, R.G. The effect of grain moisture at time of harvest on yield and milling quality of rice. The Rice Journal, Beaumont. v.70, p.16-20. 1967. 
OJAYI, O.A; CLARK, B. High velocity impact of maize kernels. Journal of Agricultural Engineering Research, London, v.67, n.2, p.97-104, 1997.

RAJANNA, B.; ANDREWS, C.H. Trends in seed maturation of rice (Oryza sativa L.). Proceedings of the Association of Official Seed Analysts, Geneva, v.60, p.188-196. 1970.

SAS Institute Inc. SAS User's Guide: statistics. Version 9.1. Cary, NC. 2003. 1 CD-ROM.

STANSEL, J.W. The rice plant its development and yield. In: DECADES OF RICE RESEARCH IN TEXAS, 6. Research Monograph, 4. The Texas Agricultural Experiment Station, College Station, Texas, 1975. p.9-21.

STEFFE, J.F.; SINGH, R.P.; MILLER JR., G.E. Harvest, drying and storage of rough rice. In: LUH, B.S. (ed.) Rice: production and utilization. Westport: Connecticut AVI Publishing, 1980. p.311-359.

TELLA, R.; BANZATTO, N.V.; AZZINI, L.E. Dormência em arroz. Campinas: Instituto Agronômico, 1977. 7p. (Circular, 82)

VIEIRA, N.R. Development and release of seed dormancy in rice (Oryza sativa $\mathrm{L}_{\text {.) }}$ as related to stage of maturity. Mississippi State, 1975. 33p. Tese (Mestrado), Mississippi State University, Mississipi, 1975.

WEBB, B.D. Rice quality and grades. In: LUH, B.S. (Ed.) Rice: production and utilization. Westport: Connecticut AVI Publishing, 1980. p.543-565. 